\title{
Intermédialités
}

Histoire et théorie des arts, des lettres et des techniques

Intermediality

History and Theory of the Arts, Literature and Technologies

\section{Élisabeth Walcker, rituels de la peinture}

\section{Éric Méchoulan}

Numéro 5, printemps 2005

Transmettre

Transmitting

URI : https://id.erudit.org/iderudit/1005500ar

DOI : https://doi.org/10.7202/1005500ar

Aller au sommaire du numéro

Éditeur(s)

Centre de recherche sur l'intermédialité

ISSN

1705-8546 (imprimé)

1920-3136 (numérique)

Découvrir la revue

Citer ce document

Méchoulan, É. (2005). Élisabeth Walcker, rituels de la peinture. Intermédialités /

Intermediality, (5), 209-211. https://doi.org/10.7202/1005500ar d'utilisation que vous pouvez consulter en ligne.

https://apropos.erudit.org/fr/usagers/politique-dutilisation/ 


\title{
Élisabeth Walcker, \\ rituels de la peinture
}

\author{
Éric Méchoulan
}

C ur la toile apparaissent les traits acides du fusain, des corps inachevés, des - taches de pastels ou de pigments jaunes, bleues, brunes, des morceaux de chiffon, des sables de couleurs différentes, et au foyer de tous ces éléments, des visages - des visages ou des masques? De la toile sort aussi sa propre trame, soit parce que, ici et là, elle n'est pas recouverte de peinture, soit parce que la peinture en très fine couche ne la fait que plus apparaître par contraste avec des reliefs pigmentés, soit parce que la toile n'est pas montée sur châssis mais souvent clouée, effilochée, inégale, à même le bois du support.

Le fond n'est peint, inégal, que pour entourer les corps et les visages, mais les corps et les visages ne s'en détachent pas tant qu'ils ne s'y coulent. Comme le spectateur se coule dans les géographies convoquées par ces rituels ou ces visages d'anges mortuaires: la transmission immédiate de pays lointains, de traditions aperçues, fait partie de cette peinture sans profondeur, qui aime à cadrer de quelques traits de fusain (Pieta) ou d'un bain inconstant de peinture blanche les corps en mouvement qui en sortent en partie (Rituels $n^{o} 1$ ).

Anges de la mort ou de l'apocalypse nous fixent de leurs yeux ici grands et jaunes au milieu d'un visage sombre, là sombres au fond d'orbites insondables dans un visage recouvert de chiffons blancs. Que l'on chiffre la mort noir sur blanc ou blanc sur noir, elle ne cesse de nous fixer. De même avec les deux Pietà, le cadavre est tantôt enserré d'une mère toute en noir, tantôt allongé sur une mère entièrement blanche, mais sans jamais qu'un visage vienne identifier la douleur : c'est la masse colorée qui suffit à reprendre la tradition. L'émotion est d'autant mieux transmise que toute une tradition est simultanément présente 
et mise à distance : l'exercice d'école de la Pietà, comme une sorte de rite de passage académique, sort transformé de ces cascades de noir et de blanc ${ }^{1}$.

Ce n'est pas faute de prêter attention aux visages, bien au contraire, ils abondent: grimaçants, hagards, pleurants, comiques. Ils dansent. Les écritures qui les accompagnent ici ou là dansent aussi, car dans ces toiles le langage est d'abord rythmes, à l'instar des corps qui répètent leurs lettres colorées dans les rituels. Le statisme obligé de la peinture révèle en fait des dynamiques, non seulement dans les silhouettes représentées, mais aussi dans les matières utilisées. Car les rythmes de ces toiles tiennent pour beaucoup aux coulées de sable, aux reliefs de peinture, aux clous mêmes qui accolent la trame irrégulièrement effrangée aux panneaux de bois. Là encore, des rituels de danse sont d'autant mieux représentés que la toile elle-même fait danser les matières, les couleurs et les formes dans des agencements en général extrêmement simples. Et pourtant ces agencements jouent eux aussi une valse hésitation entre le tryptique ou la décomposition du mouvement (Rituel, les Kouros) et le pas commun, synchrone, de la danse (Rituel, L'envoûtement) : la juxtaposition spatiale d'une longue tradition picturale est à la fois reprise et déplacée dans la synchronisation temporelle des corps dans le rituel².

Qu'est-ce donc qu'un rituel ? L'anthropologie de Claude Lévi-Strauss répondait autrefois que c'est ce qui transforme des ensembles d'événements en arrangements structuraux. Mais tout rite est dédoublé, déphasé par rapport à lui-même: il consiste tout entier en ce qu'il ressasse et réactualise; mais il tient aussi à ce qui le justifie et lui échappe, à ce qu'il virtualise. C'est pourquoi il faut un autre élément pour que les événements se rassemblent en structure: le temps, donc des rythmes. Les corps accolés les uns aux autres, à la fois proches, presque semblables, et cependant apportant chacun leurs propres scansions de

1. Élisabeth Walcker a fait d'abord des études d'art graphique à l'atelier Met de Penninghen, puis elle a étudié la peinture avec le peintre Jean Bertholle, professeur à l'Académie Nationale des Beaux Arts à Paris. Elle est actuellement professeur de dessin à l'ESAG à Paris en même temps qu'elle mène une carrière d'artiste peintre, où sa formation classique et son enseignement sont simultanément exploités et retravaillés. La transmission pédagogique fait aussi partie des masques de la peinture.

2. Elle a participé à de nombreux salons et fait des expositions personnelles en France, aux États-Unis, en Russie, au Japon, en Italie, en Espagne, au Portugal et au Danemark. On trouvera dans le texte de Dominique Viart qui accompagne le catalogue d'œuvres d'Élisabeth Walcker intitulé Carnet de voyage des éléments qui pourront compléter ces quelques notes. 
bouche, d'yeux, de variation colorée, forment des rythmes qui donnent une profondeur de temps à ces peintures volontairement ouvertes sur leurs franges accidentelles. Rien de nécessairement fini, achevé, bouclé, mais tout apparaît indispensable y compris l'inachèvement. Car, pour qu'il y ait transmission, il faut aussi laisser place à un certain vide, à un inaboutissement que ces peintures, rituellement, rendent sensible. 